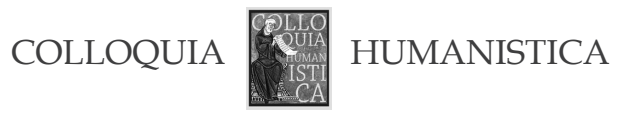

\author{
Jolanta Sujecka \\ Institute of Slavic Studies \\ Polish Academy of Sciences \\ Warsaw
}

\title{
Profile of Rafael Kamhi
}

$\mathrm{R}^{2}$ afael Moše Kamhi (1870-1970) was born in Bitola (then Monastir) in the territory of former Ottoman Macedonia. His family was of Spanish origin; one branch of which settled in Salonika. ${ }^{1}$ Kamhi was educated at the Jowish Gymnasium Alians Izraelit. and was multilingual like all the

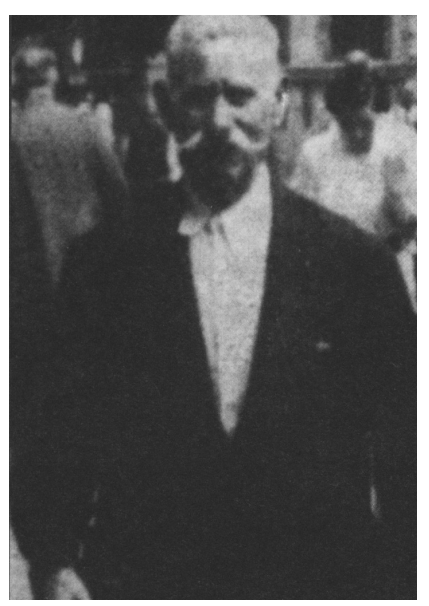

Rafael Kamhi

photographed probably in 1903 in Monastir (today Bitola). From the collection of the Museum of Holocaust in Skopje intellectuals of the Ottoman Empire: while he spoke Ladino, his mother's native tongue, he also knew Turkish, Greek, French and Bulgarian. The archives that he left contain documents in Bulgarian and Ladino.

Rafael Kamhi, as well as his brother Menteš Kamhi, was involved and committed to the Macedonian autonomist revolutionary movement which developed at the turn of the 19th century. Rafael was one of the founders of the Internal Macedonian Revolutionary Organization (IMRO-VMRO) in Salonika in 1896. Heknew G’orče Petrov (1864/65-1921) who was a teacher at the Bulgarian gymnasium in Bitola, where Kamhi was educated.

Rafael Kamhi was in charge of foreign contacts in the organisation; he was a courier between the Central Committee in Salonika and the District Committee in Bitola as well as the organisation's foreign representation in Sophia. On May 21, 1903, together with his brother Menteš, he was interned by Ottoman

1 Seе, П. Крајанов, Рафаел Моче Камхи. Илинденски дееи, од еврејско потекло, Скопје 2003. 
authorities who already knew about the uprising planned by the organisation. As published in Bulgarian, the memoirs of Kamhi (Аз войодата Скендер

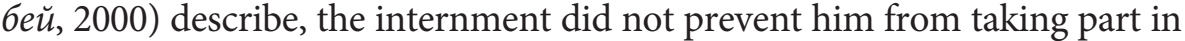
the uprising. Under the pseudonym of Skender Bey he participated in battles in the regions of Bitola and Resen.

After the fall of the uprising, Kamhi's devotion to the organisation's activity continued until 1919. Then, he finally lost hope for the autonomy of Macedonia within the Ottoman Empire or under the protectorate of the League of Nations. From 1919 and until the beginning of World War II, Kamhi lived in Salonika (a Greek city at that time).

He was saved from the transport to the concentration camp in Treblinka in 1943 thanks to Macedonian emigrant organisations in Bulgaria who asked Tsar Boris III to consent to release Kamhi as "a worthy Bulgarian." The whole Kamhi's family was killed in Treblinka.

Rafael lived alone in Sofia until 1950, when he moved to Israel. He died in Tel Aviv in 1970.

The document Borders of Macedonia, published here for the first time, is presented in two language versions: the original (written in Ladino, used by Kamhi at home and in international contacts as well) and the Polish translation by Dr. Aleksandra Twardowska. Recorded in Ladino, the text of a conversation between Theodor Herzl (1860-1904) and G'orče Petrov, one of the leaders of Macedonian autonomist movement of the revolutionary organization, was kept in the Archives of the Institute of History of the Macedonian Republic in Skopje, just like the rest of Rafael Kamhi's archives that this author is familiar with. The text was written between 1891 and 1897 and, as already mentioned, has never been published before. This author found only a Macedonian résumé of the conversation kept in the Foundation of the Holocaust in Skopje. Presumably, the document can be dated between 1891 - year of anti-Semitic pogroms in Russia - and the first Zionist congress in Basel in 1897. Theodor Herzl's famous brochure Der Judenstaad was issued in 1896. The year 1896 was significant also because it was the year when $G$ 'orče Petrov, the other participant of the conversation about Macedonia's borders, produced his monograph Матеряли nо изучаването на Македония in Sofia. At that time, Petrov was teaching at a gymnasium in Salonika under the jurisdiction of the Bulgarian Exarchate. The transcript of the conversation between Herzl and Petrov allows looking at both, the Macedonian and the Jewish question, from a different perspective, removed from particular prejudices. The connection between these questions is reflected in the very fact of this remarkable meeting which provides a meaningful context for both. It is also connected with a project seriously considered after 1881, of moving the Jews from Russia, notorious 
for pogroms, to Ottoman Macedonia. Even after the death of Herzl, the question of Jewish settlement in Istanbul and Salonika was still discussed at the Zionist congress in 1909.

It seems that the document does not contain any previously unknown sensations. Nevertheless, the text can be interesting for historians studying complicated Balkanic relations or regions with a significant occurrence of hybrid features. Kamhi's biography, ambiguous from the point of view of identity, can be interesting as well. Above all, he was a Sephardic Jew, but also a Macedonian and a citizen of the Balkans, attached like everybody else to his local homelands of Bitola and Salonika. His Macedonian patriotism was comparable to Krste Misirkov's project discussed in За македонцките работu dating from 1903, expressed in the mythologem of Macedonia in its entirety and of Macedonia as Switzerland of the Balkans, free of any nationalist, religious or linguistic domination. The fact that he first cooperated with the pro-Bulgarian branch of the Macedonian organization, as well as that later, he distanced himself from it, sprung from his hope for the realisation of the most important aim of every Macedonian, the dream of autonomy for the whole historical region, not just for its parts. In this sense, Kamhi's identity was hybrid: it belonged to Macedonia and, at the same time, to the Balkans, not seen as a European periphery, but as a border region impossible to trace on the mental maps of national ideologists. ${ }^{2}$

2 I use the information about biography of Rafael Moše Kamhi from the Archives of the Institute of History of the Macedonian Republic in Skopje and from the book of Petar Karajanov, Рaøaer Моче Камхи. Илинденски дееи, од еврејско потекло, Скопје 2003. I would like to thank Mr. Petar Karajanov, the author of the book on Kamhi and to Professor Todor Čepreganov, the Director of the Institute of Historey in Skopje and to his collaborator Teon Džingo, and to Mrs Rosa Kamhi-Ruso for their great assistance in my research of this new topic. 


\section{Las fronteras de Macedonia}

la konversasion de Geortche Petrov (1864/5-1921) kon

Teodor Herzl (1860-1904) eskrita in ladino ${ }^{1}$

Despoes del gute Hertsel demando a Geortche mi puedes dezir koalas son las foerzas ke despones para la liberasion de Macedonia si respundio Geortche la Macedonia konta cerka de dos miliones i medio de poevlo

1,230 000 Makedonianos Bulgarfiles

845000 Makedonianos Mohamedanos

140000 Makedonianos grekofiles

125000 Makedonianos Israelianos

90000 Makedonianos Kutzo Vlahos

70000 Makedonianos Serbofiles

Nuestra kapitala es Salonique con sus grandes provensas Seres, Drama, Kavala kon sus fronteras la mar Igien alasonia Olimbos altura i Katerin con la Trakia frontera [okchi lar Zambhi giomurtchina] ${ }^{2}$ frontera bulgara fin la altura Pirin i bregalnitsa frontera albaneza Bilichta [Jol] lag de Prespa lag ohrid profeta Naum kon los Rios Drin Radica monte Dechad kon la Serbia Rabetin kol i Vrania.

Moestras grandes sivdades Monastir Skople Kumanova Strumitsa, Chtip i atras 85 sivdades ke contan de 10/20 mil abitantes, vos sueto respundio Hertzel ke boen presto vuestra libertad seria serkana i voestro dezeio complido tenech razon de aprovetcharvos kon violensa ilegala Koanto por mi la kistion troca mozotros Istraelianos contamoz cerka 12 miliones de poevlo ma somos esparziados en el mundo Intero onde era menester in Palestina de ser konsentrados unos koantos miliones non kontamos ke 80 mil almas i ansin devemos de ievar pleito legal non asemeja a vozotros vos sueto boena reuchida de matchucar la kavesa del culevro d 7 kavesas ansin i mozotros ternemos su efeto. Dime geortche in otrus atentatos ke kontach azer sofriran intereses de las grandes potensias djustamente respondio geortche para ke tomen in konsiderasion.

Despoes del gute rogo Hersel a Geortche de dezirle la pozision i grandura de la Macedoina Respundio geortche la Macedoin intera es 66.725 километрос coadrados sus frontieras son la mar Egieni alturas monte Olimbos frontiera con la Traca el Rio mesta frontiera Bulgara los Rodopus fin dospat frontiera

1 Tytuł ladino nie jest tytułem oryginalnym, lecz został przetłumaczony z języka polskiego i dodany przez Aleksandrę Twardowską. W całym tekście w wersji ladino zachowano oryginalną pisownię dokumentu. Wszelkie wyjaśnienia sygnujemy inicjałami imienia i nazwiska: Jolanta Sujecka (J.S.) i Aleksandra Twardowska (A.T.).

2 Nawiasy kwadratowe oznaczają fragmenty tekstu oryginalnego, których odczytanie jest utrudnione, fragmenty nieprzetłumaczone lub fragmenty, których przekład nie jest całkowicie pewny (A.T.).

276 COLloquia Humanistica 


\section{Granice Macedonii}

\section{rozmowa G’orče Petrova (1864/5 - 1921) z Teodorem Herzlem (1860-1904) zapisana w ladino ${ }^{1}$}

Następnie dobry Herzl poprosił G’orče: „Czy możesz mi powiedzieć, jakimi siłami dysponujesz, aby wyzwolić Macedonię?” - „Tak”, odpowiedział G’orče, „Macedonia liczy około 2,5 mln ludności:

1,230 000 Macedończyków bułgarofilów,

845000 Macedończyków muzułmanów,

140000 Macedończyków grekofilów,

25000 Macedończyków Izraelitów,

90000 Macedończyków Kucowołochów,

70000 Macedończyków serbofilów².

Naszą stolicą są Saloniki, ich wielkie prowincje - Serres, Drama i Kavala, ze swoimi granicami - morzem Egejskim, Elasonem, górą Olimp i Katerini. Granica z Tracją [Okchi lar Zambhi geomurtchina]. Granica bułgarska - koniec gór Pirin i rzeka Bregalnica. Granica albańska - [Biljača], [Jol], jezioro Prespa, jezioro Ochrydzkie, św Naum, rzeki Drin i Radika, góra Dešat. Granica z Serbią - Rabetin Kol i [Vranje]”.

„Nasze duże miasta to Bitola, Skopie, Kumanovo, Strumica, Sztip i ponad 85 miast, które liczą 10-20 tysięcy mieszkańców”. „Życzę wam”, odpowiedział Herzl, „żeby wasza wolność nadeszła wkrótce i wasze marzenia się spełniły. Masz rację, działając nielegalnie. W moim przypadku jest inaczej - my Izraelici liczymy około 12 milionów, ale jesteśmy porozrzucani po całym świecie. W Palestynie powinny być skoncentrowane miliony, a liczymy nie więcej niż 80 tysięcy dusz i dlatego, w odróżnieniu od was, powinniśmy prowadzić legalne dyskusje. Wam życzę sukcesu w zdławieniu głowy węża o 7 głowach. $\mathrm{W}$ ten sposób i my będziemy mieć z tego korzyści. Powiedz mi, G’orče, czy w innych zamachach, które planujesz przeprowadzić, ucierpią interesy wielkich sił?” „Tak, właśnie”, odpowiedział G’orče, „niech się z tym liczą”.

Potem Herzl poprosił G’orče, żeby mu opisał położenie i wielkość Macedonii. G’orče odpowiedział: „Cała Macedonia to $66725 \mathrm{~km}$ kwadratowych. Jej granice to morze Egejskie i góra Olimp. Granica z Tracją to rzeka Mesta. Granica bułgarska - Rodopy

\footnotetext{
1 Tytuł dokumentu Granice Macedonii pochodzi z Archiwum Instytutu Historii w Skopje (J.S.).

2 Wydaje się, że etnograficzny obraz Macedonii z czasów osmańskich wiele zawdzięcza monografii Gorče Petrova, Матеряли по изучаването на Македония. Jest to bezcenna informacja nie tyle o krainie geograficznej, co raczej o sposobie widzenia tej krainy przez ówczesne elity ją reprezentujące. Mieszkańcy Macedonii, czyli „Macedończycy” określani są podwójnie: ze względu na konfesję - muzułmanie - i ze względu na podleganie różnym propagandom nowo powstałych państw narodowych na Bałkanach, stąd określenia „Macedończycy bułgarofile, Macedończycy serbofile, czy Macedończycy grekomani”, brak natomiast określeń chętnie używanych zarówno przez bułgarskich etnografów, jak i bułgarski dyskurs edukacyjny: Macedońscy Bułgarzy czy po prostu Bułgarzy z Macedonii. Zaproponowany przez Gorče Petrova etniczny obraz ówczesnej Macedonii dokumentuje stan nieokreśloności tożsamościowej, czy może raczej przejścia między czasami jasnych konfesyjnych kwalifikacji stosowanych przez osmańskie spisy ludności, a stanem na poły świadomego „wyboru”, który był pochodną edukacji, czyli działalności poszczególnych propagand narodowych prowadzonych przez odrodzone, młode państwa bałkańskie (J.S.).
} 
grega alasonia i la tesalia [compres/compris/compus] Caterino frontieras albanezas Pind Karaorman Jablanitza [con pris/pres/pus] char Balcan las alturas de monte negro Duganitsa osogovo i Rila Balcan i los 2 grandes lagues ohrida i prespa con Serbia tenemos frontiera Rabetin col ziberitcha vrania tenemos 52 sivdades con la capitala Macedoina Salonique que conta serca 150 mil abitantes con la majorita in todos djidios Izrailitianos con frontiera Halkidiki i detras la muntania tchaiazi in La Macedoni Egeska i la Makedonia Vardarsca tenemos 1832 kazales grandes i tchicos de 140/1000.

tutal sivdades i cazales con abitantes 2347000 dos miliones 347000 personas

1140000 Makedonianos slavianos

760000 Makedonianos Mohamedianos

125000 Makedonianos ghircomanos

108000 Makedonianos Izraelitianos

80000 Makedonianos Kutsovlahos

65000 Makedonianos Serbomanos

69000 Makedonianos Ermanis albanezis protes zinganis

Esto es la coenta i la situasion de Macedoina tomo nota Hertzel i le regrasio a Geortche por le boendad ke tuvo de darle [rensiniamietos] i le sueto bien presto de realizarson sus djustas aspirasiones in mezmo tiempo dicho malgrado ke moestro poevlo Izrael es de mas ariva 12/13 miliones ma esta esparzido in partes del munto Palestina in este mumento no conta ke una tchica manorita de 120/130 mil abitantes i geortche le incorajo diziendole los atentatos que pensamos azer las grandes potensias se despertaran.

Caro Geortche esta bien seguro ke moestras aspirasiones se realizaran non con las orasiones de Iniorantes Rabenos segun sus Iniorantes penserios i sus falsa propaganda kontra la djustisia solo con grande lavoro i grande fuersa por djustedad a un ke esto aprontado de somportar kon grande foerza i dureza todas las krtiticas i akuzasiones de parte Rabenos i savios Iniorantes rogo al todo Poderozo de non apocar mis foerzas antes de ver el poevlo djidio inpesar in masa alegres sus Imigracion aunados para tiera santa de moestros avoelos al Nido de moestros Padres.

anda un Dia sera la gloria de Israel a un ke io no terne la ventura de verlo visto non tanto presto se alcansara i mi lavoro duro non poedra dechar mis foerzas rezistir i ansin tomara fin mi vida Coanto a ti mi caro amigo geortche tu bien presto veras la liberta de la autonomia Macedoin visto il poevlo macedoniano intera mente esta atu aiundo $i$ a tu desposision intera Macedoniana i io triste de mi no tengo ni un diezeno de mi in toda la Palestina $\mathrm{i}$ ansin ti sueto todo lo boeno i presto se realizan tus aspirasiones coanto iyo esto contente de ver [motchigoar] moestra Imigrasion i moerir kontente sole de esto te abraso de corason tu amigo Teodor. 
i Dospat. Granica grecka - Elason i Tesalia, Katerini. Granice albańskie - Pindos, Karaorman, Jablanica, Szar Płanina, wysokości Czarnej Góry, Doganica, Osogovo, Riła, Bałkan $^{3}$ i dwa wielkie jeziora - Ochrydzkie i Prespa. Z Serbią mamy granicę w prowincji Rabetin Kol i [mieście Vranje].

Mamy 52 miasta ze stolicą w Salonikach, które liczą około 150 tysięcy mieszkańców, z czego większość to Żydzi, z granicą z Halkidiki i za górami [tchaiazi]. W Macedonii Egejskiej i Wardarskiej mamy 1832 dużych wsi i [140/1000] małych”.

„Ogółem w miastach i na wsiach jest 2347000 - dwa miliony 347000 mieszkańców. 1140000 Macedończyków Słowian ${ }^{4}$

760000 Macedończyków muzułmanów

125000 Macedończyków grekomanów

108000 Mcedończyków Izraelitów

80000 Macedończyków Kucowołochów

65000 Macedończyków serbomanów

69000 Macedończyków braci Albańczyków, [protes] Cyganów.

Oto liczby i sytuacja Macedonii”. Zapisał to Herzl, podziękował G’orče za jego dobroć, za [przedstawiony opis] i życzył mu szybkiej realizacji jego sprawiedliwych aspiracji. Jednocześnie powiedział: „Pomimo że nasz lud Izraela liczy 12-13 milionów, jest rozproszony po całym świecie. Obecnie w Palestynie to zaledwie mała grupa 120-130 tysięcy mieszkańców ${ }^{5 ”}$. G’orče dodał mu otuchy, mówiąc: „W wyniku zamachów, które planujemy przeprowadzić, obudzą się wielkie siły".

„Drogi G’orče. Z pewnością nasze aspiracje zrealizują się nie dzięki modlitwom Ignorantów Rabinów, ich ignoranckich myśli i ich fałszywej propagandzie przeciw sprawiedliwości, lecz dzięki wielkiej pracy i wielkiemu wysiłkowi w imię sprawiedliwości, chociaż jestem przygotowany na znoszenie z wielkim wysiłkiem i trudem wszystkich krytyk i oskarżeń ze strony Rabinów i mędrców Ignorantów. Proszę Wszechmogącego, aby nie odbierał mi sił, zanim nie zobaczę narodu żydowskiego w lepszej, weselszej kondycji, Emigracji zjednoczonej dla Ziemi Świętej naszych dziadów, Gniazda naszych ojców.

Jeszcze pewnego dnia nadejdzie chwała Izraela, chociaż nie będę miał tego szczęścia, by ją ujrzeć, ponieważ nieprędko będzie osiągnięta. Dlatego nie mogę zaniechać mojej ciężkiej pracy, muszę podtrzymać moje wysiłki i tak oto upłynie moje życie. Co do Ciebie, mój drogi przyjacielu G’orče, szybko zobaczysz wolność autonomii Macedonii, ponieważ całkowicie możesz liczyć na macedoński naród, cała Macedonia jest do Twojej dyspozycji i może Ci dopomóc. A ja, biedny, w całej Palestynie nie mam nawet dziesiątki swoich ludzi. Dlatego życzę Ci wszystkiego dobrego i niech szybko realizują się Twoje aspiracje. Co do mnie, jestem zadowolony widząc naszą Emigrację [lepszą] i tylko dlatego mogę umrzeć zadowolony. Ściskam Cię z całego serca. Twój przyjaciel Teodor”.

\section{Przekład z języka ladino Aleksandra Twardowska, przypisy historyczne Jolanta Sujecka}

\footnotetext{
3 Tutaj autor połączył opisy dwóch granic - Doganica, Osogovo (Osogowska Płanina), Riła oraz Bałkan to masywy górskie na granicy lub terenie Bułgarii, nie zaś - Albanii czy Kosowa. (A.T.).

${ }_{4}$ Wydaje się, że Petrov/Kamhi stosuje, podobnie jak spisy innych etnografów z tego okresu, przemienną kategoryzację: „Macedończycy bułgarofile” i „Macedończycy Słowianie”. Naturalnie podawane liczby są przybliżone (J.S.).

5 Chodzi tu o grupę mieszkańców żydowskich (A.T.).
} 
LAS FRONTERAS DE MACEDONIA

y. Inpoes del qute Hertioll demina 786 a geortchs mi puedes degur koalas son las faersas $k_{e}$ despones para ta Liberarion de la macedonce si res $\mathrm{m}$ n beo gearteke la Macedonia Konta cerka las miliones imedio de poeve. 1230000 Ilakedonianos Bulgayliles
845000 "Nokamedanats 140 aos Makedomanas qrecofiles 12500. Iszacllanas govor "Katso Ushathos

$\oplus$ mocstrakapitale es Salonique con sus grandes provensas Seres Irams Kevala kon susfenturas la mar Igien alasonia olimbos alture: katern con la Trakiaprontiera okcki lar zanthi gëomuitehin prontigre bulgara fin la altura Prin ibreg mi prontiera albanezas Bilich ta Jol lag de Respa lag ohrid Rofe ta, ium Roklos Bios Orim Radica noonte Dechad Ron la Serbea Rabetin Kol i vranea

Fascimile of the Ladino version of the document Macedonian Borders

280 COLLOQUiA HUMANISTICA

humanistica.indd 280

$\oplus$

2012-08-16 11:23:06 
GRANICE MACEDONII

maestras grandes siadadey ILonate silople rumanove strumitsa ehty iatras 85 hudades ke contan dep. $10 / 20$ mel abitantes, uas sueto resper ndï Hertiel ke been presto Noestro lecetad sein serkana, voestro dezeio Complido tenech razon de apravetcharwos ton violensajlegals Rarkto par mi la kiston troca mos tras istiaclianas contamar cerk I Miliones de poealo ma Somas esparzidas in elmundo Intero unde (4) era minester in Palestina de ser Apensentra las unas ko untas mi lianes

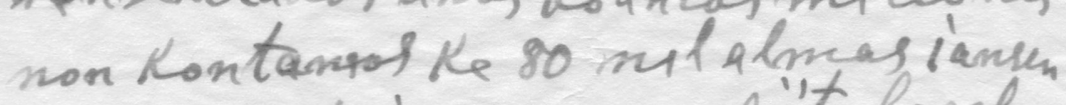
devemas de ievar un pli'to legel non asemepa lozatras vas lue to boena reuchida de matchuearla Kavera diel Culevro d Y Kaveras ansiximozptras ternemas su e feto Pime qeartehe in otrus atentatos Re Ron tach azor sofriran intereses de les grandes poten rias dyustamenteres pundio gen tche pard Retomen in Ronsiderals sox

Fascimile of the Ladino version of the document Macedonian Borders

$$
\text { COLLOQUIA HUMANISTICA } 281
$$

humanistica.indd 281

$\oplus$

2012-08-16 11:23:06 
LAS FRONTERAS DE MACEDONIA

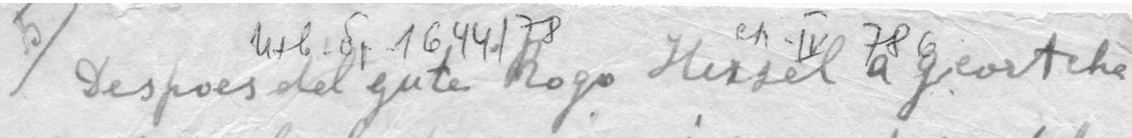
de dezpr le la posesion í qrandura dela Hacedoine Respundeo geartike la Macedo in Intira es 66, 7 25 Ku comempos coadracos susprontexus son ha mer Equenialtures monte olimbas frontera con la Treecel Rï meste prontera Bulqura los Rodopes, fin dospat prontiera gregr elasomeas a terrlia compres laterino fronteres albanezar in pera Pind Rera viman yabla nitsa conpres char Balcan las alturas de monte negro Bugenitsa asogovo;

(4) Pula kadean ilos 2 granctles laques whrede. iprespa con la Serben tenemeas lo prontier ra betin $c$ lu 31 beutche vrang tenemos $5 x$ Sivdedes con la Ca puta la the cedoina Saloniqueque conta serea so mil abitantes con la majorita un to das dyidios Izrailitianas can pron tiera Halkichri idetras la muntanea tehaiazi in lo Macedoni Egeska i la Makedo nua Vardarsca tenemos 1832 Kesales grandes itefyieonde $150 / 1000$

Fascimile of the Ladino version of the document Macedonian Borders

282 COLloquia HUMANISTICA

humanistica.indd 282

$\oplus$

2012-08-16 11:23:07 


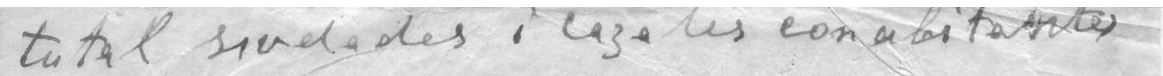
A 347 av dos m leones 347 ovo person 1. 140,000 Maredonatas s lavanos 760,000 "Nohamedenos

125,000" "qhircomanes

108000 "Yzraxlítianos

80, ado. Katsoulahos

65,000. Lurbomaras

69,000 "Ermenes al banezes paotes zingen esto es la coenta ila sutuasion Ma cedoina to mo nota thertif i le regrasco a geortche por lo boendad keturvo de dar le ren sineancets ile sueto buenpresto derea lizgrsen sus dipustas asprascoxes in mezmo tiempo dicho malgrado he moestro poevlo Iz rael es de nas areva de $12 / 13$ muliones maest espierzido in 4 partes del munto fatestime un estemumento no conto ke una tchiea mo

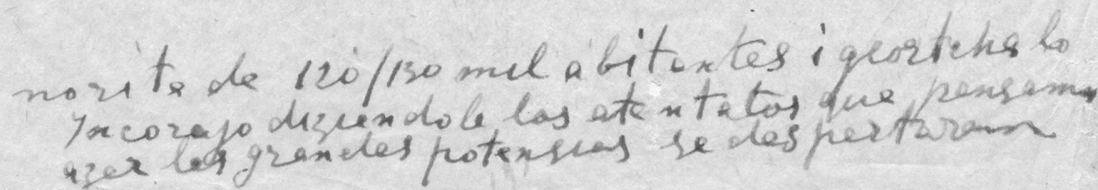

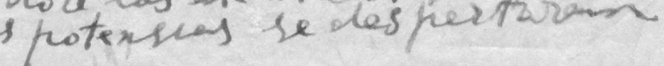

Fascimile of the Ladino version of the document Macedonian Borders 
LAS FRONTERAS DE MACEDONIA

4 Caro goat thestabuens guro Ke moestras as piras 1644 / "W " 786 Realizaran man kon las arases nes de Iniorantes Rabenas se gunsus Iniorantes pensereas A rus falsapropaiganata contrada igrande foersa par la djustedad a un ke esto aperontado de lomp artur Kongrande foersa i du reza todas teas kridices i akuza siones de parte Rabenos is Savios Inioramter rogo al tudo Poderozs de nom epocear mis foersas an tes de ver el poevlo

(⿻) pesar in mescalegres sies Inigrasiconounadsparetiera santa de maestrus avoelos al Nido de moestros Padres

Fascimile of the Ladino version of the document Macedonian Borders

284 COLLOQUia

humanistica.indd 284

2012-08-16 11:23:07 
GRANICE MACEDONII

Ande un gia sera la glaria de Iscad a unke io nom terme la Ventura de verlo vesto nontanto prestore al cansara imi lavoro duro mon poedra le charmus foer sas rezastur i amprom tomeara fin mi vida Coanto ati mi caro amig geartche tu beenprest veras lin Liberta dela antono ma in La Macedainvisto U poeulo macedanian

(1) tos mente esta atu aioudo ialu Lesposirwo intrera MacedomaneLo trustedemi nwa tenge mi um dezemo demi in toda la Palestina i amsion ti rueto todo koeno i pré to re roalizen tis aspira siones coanto. upest contente de vermo tchigar moestra Imigrasion imoerirkonten tesoludesto, Eabraso de Coraram tuanng.

Fascimile of the Ladino version of the document Macedonian Borders

COLLOQUIA HUMANISTICA 285 